\title{
Psychiatric comorbidity in patients with Posttraumatic stress disorder and Enduring personality change after catastrophic experience
}

Authors: Bradic L., Begic Dz., Lokmic-Pekic I., Hrnjica I., Ahmic M. Psychiatric hospital of Canton Sarajevo, Nahorevska 248, 71000 Sarajevo, Bosnia and Herzegovina



INTRODUCTION: Post-Traumatic Stress Disorder (PTSD) is a trauma and stress related disorder that may develop after exposure to an event or ordeal in which death, severe physical harm or violence occurred or was threatened. Traumatic events that may trigger PTSD include violent personal assaults, natural or unnatural disasters, accidents, or military combat. (1) People with PTSD continue to have intense, disturbing thoughts and feelings related to their experience that last long after the traumatic event has ended. They may relive the event through flashbacks or nightmares; they may feel sadness, fear or anger; and they may feel detached or estranged from other people. People with PTSD may avoid situations or people that remind them of the traumatic event, and they may have strong negative reactions to something as ordinary as a loud noise or an accidental touch. Enduring personality change after catastrophic experience, also known as EPCACE, is characterized by personality changes after a significant event or events. This condition may be preceded by PTSD. Symptoms may include a distrustful attitude, social isolation, or feeling a sense of threat. (2) Diagnosis Enduring personality change after catastrophic experience is not present in DSM V, unlike ICD $\mathrm{X}$, where it is listed under diagnosis $\mathrm{F} 62.0$.

AIM: Aim of this research was to examine prevalence of psychiatric comorbidity and to analyze sociodemographic characteristics in patients with PTSD and enduring personality change after catastrophic experience.

METHODS: This retrospective study included 20 (twenty) patients that were admitted in our hospital in one year with diagnosis of PTSD and Enduring personality change after catastrophic event. Data was analyzed; results are shown below.

RESULTS: Among all patient, there were $12(60 \%)$ men and 8 $(40 \%)$ women. There were $11(55 \%)$ patients with PTSD diagnosis (4 women and 7 men). Enduring personality change after catastrophic experience diagnosis had 9 patients $(45 \%)-$ 4 women and 5 men. Comorbidity was present in 17 patients $(85 \%)-7$ women and 10 men. The most common comorbidities in women were $F 33.2$ and $F 32.1$ ( 5 women, $62.5 \%$ ); in men $\mathrm{F} 10.2$ and $\mathrm{F} 10.1$ (7 men, 58.3\%). We had 15 $(75 \%)$ married patients ( 6 women and 9 men). Twelve patients $(60 \%)$ had high-school level of education, of which 5 women and 7 men. Unemployed were 7 (50\%) women and 7 (50\%) men.

CONCLUSION: Results implied that in women with PTSD and Enduring personality change after catastrophic experience diagnosis, the most common comorbidities were depressive disorders, while in men were Mental and behavioral disorders due to use of alcohol. Analysis of sociodemographic characteristics demonstrated that unemployment was present in high percentage equally distributed among both sex, and that most of the patients were married.

References:

1. https://www.patientslikeme.com/conditions/2697-enduring-personality-change-aftercatastrophic-experience

2. https://www.psychologytoday.com/us/conditions/post-traumatic-stress-disorder 